\title{
A comparative study of intrathecal dexmedetomidine, fentanyl and magnesium sulphate as adjuvants to $0.5 \%$ hyperbaric bupivacaine for lower abdominal surgeries \\ R.K.kamel, M. A.AL-Rabiey, A.A.Hassan, and T.E.A.Sakr
}

Anesthesiology and Intensive Care, Dept., Faculty of Medicine, Benha Univ., Benha, Egypt

Email:R.K.kamel@yahoo.com

\begin{abstract}
Goal \& Background: This research was aimed at comparing the effect, onset and duration of sensory and motor block, hemodynamic effects, analgesic effects and the adverse effects of intrathecal dexmedetomidine, fentanyl and magnesium sulphate to $0.5 \%$ hyperbaric bupivacain. Methods: the research is done on 60 ASA I or II patients aged 18 to 60 years planned for the lower abdominal procedure under a spinal anaesthetic, randomly assigned to four equal groups (25 patients each) by means of a computer generated random number table: Group I: $15 \mathrm{mg}$ of 0.5 percent intrathecally hyperbolic bupivacaine $+0.5 \mathrm{ml}$ of normal saline received. Group II: $15 \mathrm{mg} 0.5 \%$ hyperbaric $+50 \mathrm{mg} \mathrm{MgSO} 4$ intrathecally received. Group III: $15 \mathrm{mg}$ hyperbaric bupivacaine Plus $25 \mu \mathrm{g}$ intrathecally of fentanyl. Group IV: receives $15 \mathrm{mg}$ of $0.5 \mathrm{percent}$ hyperbaric bupivacaine and $5 \mu \mathrm{g}$ of diluted intrathecally dexmedetomidine. Results and Conclusion: Magnesium sulphate has a speedier start, although both fentanyl and dexmedetomidine have a longer duration and an enhanced block power. As a local anaesthetic addition, magnesium and dexmedetomidine may have fewer side effect than fentanyl. Intrathacal injection with bupivacaine of dexmedetomidine and $\mathrm{MgSO} 4$ was beneficial in lowering the occurrence of post-SA tearing. We are thus encouraging the use of MgSO4 since it is more physiologically available, more accessible and considerably cheaper than dexmedetomidine in most operating theatres. Magnesium offers hemodynamic stability, with less side effects than fentanyl.
\end{abstract}

Keywords: Intrathecal, Dexmedetomidine, Fentanyl, Magnesium sulphate, $0.5 \%$ hyperbaric bupivacaine, Abdominal surgeries.

\section{Introduction}

While spinal anaesthetic is tempting for reasons of speed, simplicity and confidence, conventional anaesthetic procedures have been shown to be troublesome in ambulatory surgery. Longer duration of the spinal block is useful for both lengthy and postoperative pain management methods. [1]

In ambulatory surgery, 0.5 percent heavy bupivacaine may delay the motor function recovery and lead to a postoperative analgesical duration that is likewise restricted. Therefore, an intrathecal addition to these local anaesthetics is a reliable and replicable approach of extended post-operative analgesia to extend the anaesthetic duration. As an adjuvant to extend spinal anesthesia's duration, many drugs such as fentanyl, magnesium sulphate, and dexmedetomidine have been used [2].

Spinal anaesthesia with a low dosage of local anaesthetic in conjunction with opioid has increased in popularity in recent years as a result of a significantly quicker recovery than conventional anaesthetic techniques, high success rates, and patient satisfaction, and less use of resources than general anesthesia [3].

The use of opioids for spinal anaesthesia in combination with local anaesthetic has been linked to lowered pain rates and lower analgesic need for the postoperative period. Intrathecal fentanyl is a lipophilic opioid receptor agonist that has an impact combined in the dorsal horn of the spinal cord with opioid receptors and may have supraspinal distribution and activity. Fentanyl is developed to offer postoperative analgesia after SAB. Results from prior research have shown that intrathecal fentanyl not only improves analgesic dosages but also does not delay recovery when added to subtherapeutic doses of local anaesthesia. [4]

Biswas et al. [5] have indicated that fentanyl and bupivacaine may possibly synergize, fentanyl being an efficient hyperbaric adjuvant for caesarean delivery, as demonstrated by several trials [6]. While intrathecal fentanyl has a great intra- and post-operative anaesthetic profile, it has no adverse impact which has been taken into account in the greater prevalence of pruritus [7].

Various trials have been conducted employing fentanyl with a dosage of $25 \mu \mathrm{gm}$ intrathecally adjuvant to hyperbaric bupivacaine for lower Abdominal Surgery [8].

The goal of this research is to compare the effectiveness, onset and duration of the sensory and engine block, hemodyinamic effects, analgesic effects and side effects in the lower abdominal surgery with intrathecal dexmedetomidine, fentanyl and magnesium sulphate as adjuvant to $0,5 \%$ hyperbaric bupivacaine.

\section{Patients and methods}

After approval from the local ethical committee of Benha University Hospital and after obtaining patient's informed written consent, this prospective, randomized, controlled, double-blind study was conducted on 60 patients of ASA I or II, between 18 and 60 years of age, scheduled for lower abdominal operation under spinal anesthesia, they will be randomly allocated using a computer generated random number table into four equal groups (25 patients each):

- Group I: receive $15 \mathrm{mg}$ of $0.5 \%$ hyperbaric bupivacaine intrathecally $+0.5 \mathrm{ml}$ of Normal saline. (The total volume injected will be $3.5 \mathrm{ml}$ ) 
- Group II:receive $15 \mathrm{mg}$ of $0.5 \%$ hyperbaric bupivacaine $+50 \mathrm{mg} \mathrm{MgSO} 4$ intrathecally. (The total volume injected will be $3.5 \mathrm{ml}$ )

- Group III: receive $15 \mathrm{mg}$ of $0.5 \%$ hyperbaric bupivacaine $+25 \mu \mathrm{g}$ of fentanyl intrathecally. (The total volume injected will be $3.5 \mathrm{ml}$ )

- Group IV: receive $15 \mathrm{mg}$ of $0.5 \%$ hyperbaric bupivacaine $+5 \mu \mathrm{g}$ of diluted, Dexmedetomidine intrathecally (Dexmedetomidine $100 \mu \mathrm{g} / \mathrm{mL}$ will be diluted in $10 \mathrm{ml}$ normal saline). (The total volume injected will be $3.5 \mathrm{ml}$ ).

\subsection{Exclusion Criteria}

Patients with morbid obesity, cardiac diseases, hepatic diseases, renal diseases, diabetes mellitus with polyneuritis, American Society of Anesthesia III-IV, hypertensive patient receiving therapy with adrenergic receptor antagonist, calcium channel blocker and/or angiotensin converting enzyme inhibitor, coagulation disorders, those receiving any anticoagulants, any history of allergy to local anesthetic or other drugs used in the study, patients on examining drugs, any contraindication to spinal anesthesia (patient refusal, infection at puncture site and increased intracranial tension and Patients with psychiatric illness and neurologic disease was excluded.

\subsection{Preoperative}

All patients was subjected initially to medical history, a complete physical examination, and laboratory investigations Included complete blood picture, prothrombin time, partial thromboplastin time, INR, liver and kidney function tests, random blood sugar. Patients will be familiarized with visual analogue scale (VAS) and its use for measuring the postoperative pain. In the operating room, a peripheral wide bore intravenous line will be inserted, and the baseline of standard parameters was recorded, they was preloaded with intravenous Ringer's solution at the rate of $10-15 \mathrm{ml} / \mathrm{kg} 30$ minutes before anesthesia.

\subsection{Intraoperative}

The procedure was done under full sterile precautions, including gown, mask and gloves. With the patient in sitting position the skin over the back will be prepared with iodine containing sterilizing solution and draped with a sterile towel. As per protocol the interspace chosen will be L3-L4. A 25G Quincke spinal needle was introduced into L3 -L4 intervertebral space gently in the midline until it reached the subarachnoid space. The position of the needle in the subarachnoid space was confirmed by dripping of cerebrospinal fluid through the needle freely. After injecting the drugs, the needle was withdrawn and the patient will turn supine.

\subsection{Outcome}

Assessing the Onset of sensory analgesia (defined as time in minutes to reach highest sensory level) was tested every minute after intrathecal injection until it reached the highest level. Duration of analgesia (defined as the time of maximum sensory block till request of the first dose of analgesia with VAS score $>5$ ). Sensory assessment will be carried out with pin prick method using a $26 \mathrm{G}$ hypodermic needle, bilaterally along the mid-clavicular line to measure the Sensory level of analgesia (defined as segmental level of highest sensory analgesia).

\subsection{Statistical analysis}

Statistical analysis was carried out using statistical package for social science (SPSS version 16). As follow: Qualitative data was described using number and percentage. Quantitative data was described using mean and SD for normally distributed data. Qualitative data will be analyzed by using Chi-square and/or fisher exact tests. Quantitative data was analyzed by using one way ANOVA test. For significant ANOVA test, further post hoc analysis was done to detect the significant group.

\section{Results}

There were no significant differences between all groups as regard age, gender and ASA. P values were $0.723,0.903$ and 0.782 respectively. Table 1

Onset of surgery analgesia showed overall significance between all groups ( $\mathrm{P}$ value $<0.001$ ). Pairwise analysis showed that group I was significantly higher compared to group II, III and IV. Also group II and III was significantly higher compared to group IV. Duration of analgesia showed overall significance between all groups ( $\mathrm{P}$ value $<0.001)$. Pairwise analysis revealed that Group I was significantly lower compared to group II, III and IV. Group II was significantly lower compared to group III and IV. Group III was significantly lower compare to group IV. There were no significant differences between all groups as regard duration of surgery. $\mathrm{P}$ value was 0.507 , table (2).

Table (1) General characteristics.

\begin{tabular}{|c|c|c|c|c|c|c|c|}
\hline & & & Group I & Group II & Group III & Group IV & P value \\
\hline Age (years) & Mean \pm SD & & $41 \pm 12$ & $37 \pm 13$ & $38 \pm 14$ & $39 \pm 11$ & 0.723 \\
\hline \multirow[t]{2}{*}{ Gender } & Males & n $(\%)$ & $18(72.0)$ & $16(64.0)$ & $18(72.0)$ & $18(72.0)$ & 0.903 \\
\hline & Females & n $(\%)$ & $7(28.0)$ & $9(36.0)$ & $7(28.0)$ & $7(28.0)$ & \\
\hline \multirow[t]{2}{*}{ ASA } & Grade I & n $(\%)$ & $12(48.0)$ & $12(48.0)$ & $15(60.0)$ & $12(48.0)$ & 0.782 \\
\hline & Grade II & n (\%) & $13(52.0)$ & $13(52.0)$ & $10(40.0)$ & $13(52.0)$ & \\
\hline
\end{tabular}

One Way ANOVA was used for age. Chi-square test was used for categorical data. 
Total dose of analgesia consumption showed an overall significance between all groups. $\mathrm{P}$ value was $<0.001$. Pairwise analysis revealed that group I was significantly higher compared to group II, III and IV. Group II was significantly lower compared to group III and IV. table (3)

At 1h. There was an overall significance between groups. $\mathrm{P}$ value $<0.001$. Pairwise analysis revealed that group I was significantly higher compared to groups II, III and At 2h; There was an overall significance between groups. $\mathrm{P}$ value $<0.001$. Pairwise analysis revealed that group IV was significantly lower compared to groups I, III and III. At 4h; There was an overall significance between groups. $\mathrm{P}$ value $=0.001$. Pairwise analysis revealed that group III was significantly higher compared to groups I and II, At 6h; There was an overall significance between groups. $\mathrm{P}$ value $=0.001$. Pairwise analysis revealed that group I was significantly higher compared to group II, At 8h: There was an overall significance between groups. $\mathrm{P}$ value $=0.037$. Pairwise analysis revealed that group III was significantly higher compared to group II. At 12h; There was an overall significance between groups. $\mathrm{P}$ value $=0.037$. Pairwise analysis revealed that group II was significantly higher compared to group III, table (4)

There was an overall significance as regard pruritis between all groups. $\mathrm{P}$ value was $<0.001$. Pairwise analysis revealed that group III was significantly higher compared to group I, II and IV. There was an overall significance as regard shivering between all groups. $\mathrm{P}$ value was $<0.001$. Pairwise analysis revealed that group I was significantly higher compared to group II, III and IV. There were no significant differences between all groups as regard nausea and vomiting fig. (1).

Table (2) Duration of surgery \& analgesia characteristics.

\begin{tabular}{|c|c|c|c|c|c|c|c|c|c|}
\hline & \multicolumn{2}{|c|}{ Group I } & \multicolumn{2}{|c|}{ Group II } & \multicolumn{2}{|c|}{ Group III } & \multicolumn{2}{|c|}{ Group IV } & \multirow[b]{2}{*}{ P value } \\
\hline & Mean & \pm SD & Mean & \pm SD & Mean & \pm SD & Mean & \pm SD & \\
\hline Duration of surgery (min) & 95 & 21 & 106 & 29 & 97 & 26 & 100 & 28 & 0.507 \\
\hline Onset of sensory analgesia (min) & 7.1 & 1.5 & 3.8 & 0.6 & 3.7 & 0.7 & 2.8 & 0.3 & $<0.001$ \\
\hline Duration of analgesia (min) & 110 & 11 & 150 & 9 & 191 & 17 & 202 & 7 & $<0.001$ \\
\hline
\end{tabular}

One Way ANOVA was used. Pairwise comparisons were Bonferroni adjusted

Table (3) Total dose of analgesia consumption.

\begin{tabular}{lllllll}
\hline & & Group I & Group II & Group III & Group IV & P value \\
\hline Total analgesia consumption $\mathbf{m g} / \mathbf{k g}$ & Mean \pm SD & $8 \pm 3$ & $6 \pm 2$ & $5 \pm 1$ & $5 \pm 1$ & $<0.001$ \\
\hline
\end{tabular}

One-way ANOVA was used. Pairwise comparisons were Bonferroni adjusted

Table (4) Visual analogue scale in all groups.

\begin{tabular}{lccccccccc}
\hline & \multicolumn{2}{c}{ Group I } & \multicolumn{2}{c}{ Group II } & \multicolumn{2}{c}{ Group III } & \multicolumn{2}{c}{ Group IV } \\
& Median & Range & Median & Range & Median & Range & Median & Range & P value \\
\hline At $\mathbf{1} \mathbf{~ h r}$ & 1 & $0-2$ & 1 & $0-1$ & 1 & $0-1$ & 0 & $0-1$ & $<0.001$ \\
At $\mathbf{~} \mathbf{~ h r}$ & 1 & $0-2$ & 1 & $0-2$ & 1 & $0-2$ & 0 & $0-1$ & $<0.001$ \\
At $\mathbf{4} \mathbf{~ h r}$ & 1 & $0-2$ & 1 & $0-2$ & 2 & $1-4$ & 1 & $1-2$ & 0.001 \\
At $\mathbf{6} \mathbf{~ h r}$ & 2 & $1-6$ & 1 & $0-3$ & 2 & $1-3$ & 2 & $1-3$ & 0.003 \\
At $\mathbf{6} \mathbf{~ h r}$ & 4 & $1-6$ & 4 & $2-6$ & 5 & $3-6$ & 4 & $3-6$ & 0.037 \\
At $\mathbf{1 2} \mathbf{~ h r}$ & 3 & $1-5$ & 5 & $0-6$ & 2 & $1-6$ & 3 & $1-5$ & 0.03 \\
At $\mathbf{2 4} \mathbf{~ h r}$ & 4 & $0-5$ & 2 & $1-5$ & 3 & $1-5$ & 3 & $2-5$ & 0.179 \\
\hline
\end{tabular}

Kruskal Wallis test was used. Pairwise comparisons were Bonferroni adjusted

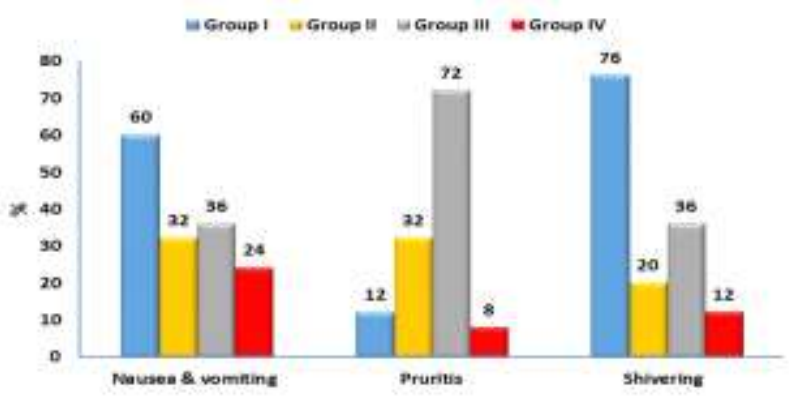

Fig. (1) Side effect percentage. 


\section{Discussion}

Regarding sensory beginnings, it was till the greatest sensory level had been attained, although Shukla and his colleagues [9] studied it just till T10. In another investigation, Sunil et al.[10] found that the onset in dexmedetomidine was $10 \mu \mathrm{g}$ quicker than in bupivacain groups compared to $5 \mu \mathrm{g}$ and quicker.

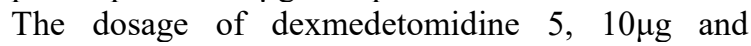
intrathecal bupivacaine was compared with Al Mustafa et al [11] and the effect was shown to be dose-based and reversing the sensory and motor blocks. However, doserelated lengthening of the duration of intrathecal fentanyl spinal analgesia is not. In non-obstetric patient investigations, the high quality of perioperative analgesia was shown at dosage $25 \mu \mathrm{g}$ fentanyl for spinal anaesthetic augmentation. Based on the results of the prior investigation, fentanyl at a dosage of $25 \mu \mathrm{g}$ was utilised in the current investigation to augment spinal bupivacaine.

In line with the current investigation, intrathecal dexmedetomidine was more quickly administered as an adjuvant to bupivacain compared to magnesium sulphate and hyperbaric bupivacaine [9].

In our investigation, $50 \mathrm{mg}$ of magnesium sulphate was added to the sensory and motor block for extended durations. The impact of adding magnesium to intrathecal bupivacaine has been explored in prior clinical studies and an increased analgesic duration of 18-48 minutes has been found across many obstetric and non-obstetric groups with intrathecal magnesium. [12] Our findings highlight the importance of magnesium sulphate as an efficient intraathecal adjuvant (NMDA antagonist).

Regarding the arterial oxygen saturation, there was no significant change throughout the measurement intervals between the three groups which might be caused by the additional oxygen delivery using a facial mask. This was in accordance with Sunil et al. [10].

In the current investigation, the duration of the motor block in individuals in the dexmedetomidine group has increased considerably. Extension of the engine block by $\alpha 2$-adrenoreceptor agonists may be the consequence of these agonists being bound to motor neurons in the spinal cord dorsal horn. [13]

In the present investigation, there was a statistically significant difference in dexmedetomidine group between the three groups with a quicker onset conclusion than other groups. Moreover, in comparison with fentanyl as adjuvants to intrathhecal bupivacaine on work result, Ogan et al [14] reported a quicker motor onset in the dexmedetomidine group. This was consistent with the conclusion of Shukla et al [9].

With respect to VAS, in comparison with the bupivacaine group, Gupta et al.[2] found lower VAS values in the dexmeditomidine group.

With respect to side effects such as Nausea, vomiting, shivering, pruritus, respiratory depression and drowsiness, Nausea and vomiting were the most in bupivacaine alone, followed by fentanyl group and, with consent of Prakesh et al., less in the dexmedetomidine group [15].

However, in comparison, Hala et al.[16] who studied various intrathecal doses of dexmedetomidine $(5,10$ and $15 \mu \mathrm{g})$ added to bupivacaine demonstrated significantly more high levels of sedation when using $15 \mu \mathrm{g}$, which might be useful as an alternative to epidural or prolonged general treatment in the present study. However, in older and high risk surgical patients such high sedation rates may be hazardous due to the danger associated with excessive sedation and respiratory depression. Also, despite intravenous magnesium increasing the prevalence of confusion and sleepiness in eclamptic patients, there was no substantial sedative impact of intrathecal magnesium in our investigation.

The present investigation showed that the incidence of post-SA shivering was considerably decreased after injections of both dexmedetomidine $(10 \mu \mathrm{g})$ and $\mathrm{MgSO} 4$ $(50 \mathrm{mg})$. Fentanyl and bupivacaine alone were higher in the number of individuals who experienced shivering and needed meperidine.

The effectiveness and safety of dexmedetomidine and magnesium sulphate have been shown to be effective and safe for preventing and treating the shivering after $\mathrm{SA}$, which is equivalent or superior to other adjuvants and has less side effects.

\section{Conclusion}

Magnesium and dexmedetomidine may be less of a side effect than fentanyl for lower abdominal surgery as an addition to local anaesthetic in spinal anaesthesia.

\section{References}

[1] A.El-Attar, M.A.Aleem, R.Beltagy, and W.Ahmed, "A comparative study of intrathecal dexmedetomidine and fentanyl as additives to bupivacaine," Res. Opin. Anesth. Intensive Care, vol. 2,pp. 43, 2015.

[2] R.Gupta, R.Verma, J.Bogra, M.Kohli, R.Raman, and J.K.Kushwaha, "A comparative study of intrathecal dexmedetomidine and fentanyl as adjuvants to bupivacaine," J. Anaesthesiol. Clin. Pharmacol., vol. 27,pp. 339, 2011.

[3] A.L.Khan, R.B.Singh, R.K. ripathi, and S.Choubey, "A comparative study between intrathecal dexmedetomidine and fentanyl as adjuvant to intrathecal bupivacaine in lower abdominal surgeries: a randomized trial," Anesth. essays Res., vol. 9, p. 139, 2015.

[4] S.A.Schug and S.Ting, "Fentanyl formulations in the management of pain: an update," Drugs, vol. 77, pp. 747-763, 2017.

[5] B.N.Biswas, A. Rudra, B.K.Bose, S.Nath, and S.Chakrabarthy, "Intrathecal Fentanyl With Hyperbaric Bupivacaine Improves Analgesia During Caesarean Delivery And In Early PostOperative Period.," Indian J. Anaesth., vol. 46, pp. 469, 2002.

[6] M.B.Khezri, M.Rezaei, M.D.Reihany, and E.H.S.Javadi, "Comparison of postoperative 
analgesic effect of intrathecal clonidine and fentanyl added to bupivacaine in patients undergoing cesarean section: a prospective randomized double-blind study," Pain Res. Treat., vol. 2014, pp. 1-13, 2014.

[7] E. Balaji, "A Randomized Double Blinded Study Comparing the Effect of Adding Dexmedetomidine and Fentanyl with $0.5 \%$ Hyperbaric Bupivacaine in Spinal Anaesthesia for Elective Caesarean Section." Thanjavur Medical College, Thanjavur, vol. 3, pp. 12-19, 2016.

[8] P.R.Dhumal, E.P.Kolhe, V.B.Gunjal, and V.A.Kurhekar, "Synergistic effect of intrathecal fentanyl and bupivacaine combination for cesarean section," Int J Pharm Biomed Res, vol. 4, pp. 5056, 2013.

[9] D.Shukla, A.Verma, A.Agarwal, H.D.Pandey, and C.Tyagi, "Comparative study of intrathecal dexmedetomidine with intrathecal magnesium sulfate used as adjuvants to bupivacaine," J. Anaesthesiol. Clin. Pharmacol., vol. 27, p. 495, 2011.

[10] B.VSunil, K.S.Sahana, and P.R.Jajee, "Comparison of dexmedetomidine, fentanyl and magnesium sulfate as adjuvants with hyperbaric bupivacaine for spinal anaesthesia: a double blind controlled study," Int J Recent Trends Sci Tech, vol. 9, pp. 14-19, 2013.

[11] M.M.Al-Mustafa et al., "Effect of dexmedetomidine added to spinal bupivacaine for urological procedures," Saudi Med J, vol. 30, pp. 365-370, 2009.

[12] T. Y. E. Hamawy and M. H. Mohamed, "Comparison of intrathecal magnesium, dexmedetomidine, or placebo combined with bupivacaine $0.5 \%$ for patients with mild preeclampsia undergoing cesarean section," AinShams J. Anaesthesiol., vol. 8, no. 2, p. 230, 2015.

[13] Y.Sun, Y.Xu, and G.-N. Wang, "Comparative evaluation of intrathecal bupivacaine alone, bupivacaine-fentanyl, and bupivacainedexmedetomidine in caesarean section," Drug Res. (Stuttg)., vol. 65, pp. 468-472, 2015.

[14] S.Fyneface-Ogan, O. Gogo Job, and C. E. Enyindah, "Comparative effects of single shot intrathecal bupivacaine with dexmedetomidine and bupivacaine with fentanyl on labor outcome," Int. Sch. Res. Not., vol. 2012, pp. 765-772, 2012.

[15] P. M. Limbu, S.Khatiwada, B. P. Sah, S. N.Singh, K. Pokharel, and R. Maharjan, "Intrathecal magnesium sulfate as analgesic and anaesthetic adjunct to bupivacaine in patients undergoing lower extremity orthopaedic surgery," J. Soc. Anesthesiol. Nepal, vol. 4, pp. 74-80, 2017.

[16] H.E.Eid, M.A.Shafie, and H. Youssef, "Doserelated prolongation of hyperbaric bupivacaine spinal anesthesia by dexmedetomidine," Ain Shams J Anesth., vol. 4, no. 2, pp. 83-95, 2011. 